\title{
EDITORIAL
}

\section{Let 2020 begin}

\author{
Ian Yeoman ${ }^{1}$
}

Published online: 1 February 2020

c) Springer Nature Limited 2020

Vinod's paper on Blockchain in Travel examines what is the blockchain and what it means for travel and Revenue Management. This article clarifies the concepts and applications of blockchain, which practitioners will find useful. Phumchusr's paper is its essences addresses the proposition on how accurate hotel daily demand forecasting is an important input for hotel revenue management, in particular the importance of machine learning for complex processing of multiple variables. Singh and Guan-Ru employed a model of twoperiod in which the manufacturer determines a price floor and drafts output of production precedingly to the attainment of certainty by demand on the assumption that the closer the distance between the minimum price and the price during the high phase of demand, the higher is the degree of price inertia. The study found that first, market price volatility increases with a manufacturer's market power in the absence of retailers, but this relationship is reversed after downstream members are introduced. Second, binding price floor makes prices less responsive to demand and cost shocks during a state of low demand than in the state of high demand and this asymmetry might be a characteristic of competitive markets. Third, the retail price in a highly concentrated retail market might be lower than that in a retail market with fierce competition. Fourth, price inertia increases with the durability of the commodity, suggesting the need for caution when using the rigid prices of durable goods as an indicator of strong demand. Fifth, when the uncertainty of demand and credit return are not tremendous, the presence of both a price floor and a return policy attenuates price competition in the retail market during the phase of low demand but intensifies it during the high phase of demand. Finally, he longer the contract duration between the manufacturer and retailers, the higher is the degree of price rigidity, highlighting that a cooperative relationship between channel members should be considered in studies of price staggering.

Ian Yeoman

ian.yeoman@vuw.ac.nz

1 Victoria University of Wellington, Wellington, New Zealand
Drabas and Wu's study on market spill assumes that the true demand of airline tickets is defined as the number of passengers that would book a particular flight if there was no capacity constraint. Estimating the true demand plays a crucial role in airline revenue management and pricing. In the paper, the authors developed a true demand unconstraining model that incorporated passenger choice models, allowing us to simultaneously estimate true demand for all booking classes in a market. The findings present a method that lets airlines estimate true demand for their own flights but also allows them to gauge the market situation among competitors. $\mathrm{Xu}$ et al's paper on online cooperation mechanism between restaurants and third-part websites as Increasing numbers of restaurants pay a commission to seek a business relationship with a third-party website as an alternative distribution channel for traditional offline selling. Using a Stackelberg game is established to study online pricing strategies of a restaurant, as well as the optimal service effort level of a third-party website. Two optimal cooperative strategies in different scenarios are obtained, which are comprehensively influenced by the restaurant's retail price and the website's user base.

The general trend in the airline industry has been to generate ancillary revenue by offering additional services says Shao and Kaurermann. Instead of completely separating ancillary services from tickets as optional components, most of the traditional airlines offer the so-called branded fares which bundle some of the ancillary components to an inclusive fare preventing a possible negative impact on the customers' perception and brand image (mixed bundling). The study evaluated different bundle-pricing policies within the mixed bundling context using statistical regression methods to infer individual behaviour. The paper revealed how aggregate data still allows us to investigate individual behaviour and data analysis reveals the existence and variability of price elasticity.

Publisher's Note Springer Nature remains neutral with regard to jurisdictional claims in published maps and institutional affiliations. 